\title{
Continue Your beyond Budgeting Journey with Help from Agile, Lean and Scrum
}

\author{
Helge Eikeland \\ Statoil, Forusbeen 50, N-4035 Stavanger, Norway \\ heeik@statoil.com
}

\begin{abstract}
Statoil is introducing the so-called "Scrum" method in business support project throughout the company with the goal of achieving better, cheaper and more sustainable results in a shorter time. Scrum is based on the principles of 'lean' and 'agile' and is closely related to Beyond Budgeting. Helge Eikeland, Statoil will explain the principles of Scrum and how they are beneficially using it in their Beyond Budgeting implementation.
\end{abstract}

